Editor's Note: To commemorate the 40th anniversary of the Society for Neuroscience, the editors of the Journal of Neuroscience asked several neuroscientists who have been active in the society to reflect on some of the changes they have seen in their respective fields over the last 40 years.

\title{
Memory and Brain Systems: 1969-2009
}

\author{
Larry R. Squire \\ Veterans Affairs Healthcare System, San Diego, California 92161, and Departments of Psychiatry, Neurosciences, and Psychology, University of California, \\ San Diego, San Diego, California 92093
}

During the past two centuries, the study of learning and memory has been central to three disciplines: first philosophy, then psychology, and now biology. Biological inquiry began in earnest during the latter part of the 20th century, as technological advances made it feasible to move beyond description to explorations of mechanism. The founding of the Society for Neuroscience in 1969 occurred at about the time that cellular studies and studies of brain systems were beginning to bear fruit. Yet, it is instructive to consider that the Society was founded before the discovery of place cells (1971), before the discovery of long-term potentiation (1973), before an animal model of human memory impairment was established (1978) or evidence of multiple memory systems (1980), before Aplysia and Drosophila became productive simple systems for studying memory, and before the development of any neuroimaging technology. Indeed, it is not an exaggeration to say that the better part of what is now understood about the neuroscience of learning and memory became known after the Society was established. This article highlights these recent achievements, focusing on the structure and organization of memory and the brain systems that support memory. It is hoped that readers will appreciate that because of format and space constraints a considerable amount of excellent work could not be cited and that the coverage here provides only an overview - and a personal overview at that - of some of the notable developments.

The modern era of memory research can be said to have begun in 1957 when Brenda Milner described the profound effects on memory of bilateral medial temporal lobe resection, performed to relieve epilepsy in a patient who became known as H.M. (Scoville and Milner, 1957; Squire, 2009). H.M. exhibited profound forgetfulness against a background of largely intact intellectual and perceptual functions. The findings from H.M. established three fundamental principles that continue to guide experimental work. First, memory is a distinct cerebral function, separable

Received July 23, 2009; revised Aug. 24, 2009; accepted Aug. 24, 2009.

This work was supported by the Medical Research Service of the Department of Veterans Affairs, National Institute of Mental Health Grant 24600, and the Metropolitan Life Foundation. I thank Cristina Alberini, Annette Jeneson, Stefan Leutgeb, Matthew Shapiro, Christine Smith, Ryan Squire, and John Wixted for their helpful comments.

Correspondence should be addressed to Larry R. Squire, Veterans Affairs Medical Center 116A, 3350 La Jolla Village Drive, San Diego, CA 92161. E-mail: Isquire@ucsd.edu.

DOI:10.1523/JNEUROSCI.3575-09.2009

Copyright $\odot 2009$ Society for Neuroscience $\quad$ 0270-6474/09/2912711-06\$15.00/0 from other cognitive abilities. Second, because H.M. did as well as others his age at retaining a number or a visual image for a short time, the medial temporal lobe is not needed for immediate memory. Third, the structures damaged in H.M. are not the ultimate repository of memory, because he retained his remote childhood memories.

It subsequently became clear that only one kind of memory, declarative memory, is impaired in H.M. and other similar patients (Cohen and Squire, 1980). Thus, memory is not a unitary faculty of the mind but is composed of multiple systems that have different operating principles and different neuroanatomy (Squire, 2004). The major distinction is between the capacity for conscious, declarative memory about facts and events and a collection of unconscious, nondeclarative memory abilities, such as skill learning and habit learning. In the case of nondeclarative memory, experience modifies behavior but without requiring any conscious memory content or even the experience that memory is being used. Nondeclarative memory is expressed through performance. Declarative memory is expressed through recollection, as a way of modeling the external world. The different memory systems operate in parallel to support behavior. For example, an aversive childhood event such as being knocked down by a large dog might lead to a stable declarative memory for the event itself as well as a long-lasting fear of dogs (a nondeclarative memory) that is experienced as a personality trait rather than as a memory.

Efforts to achieve an animal model of human memory impairment succeeded initially in the monkey (Mishkin, 1978). Cumulative behavioral work, together with neuroanatomical studies, eventually identified the anatomical components of the medial temporal lobe memory system that support declarative memory (Squire and Zola-Morgan, 1991): the hippocampus (including the CA fields, the dentate gyrus, and the subicular complex), together with the adjacent entorhinal, perirhinal, and parahippocampal cortices that make up much of the parahippocampal gyrus. The behavioral work in the monkey reproduced important features of human memory impairment, emphasizing the key idea that only tasks of declarative memory should be expected to reveal an impairment. The neuroanatomical studies identified the boundaries and the connectivity of the important areas, initially in the monkey and subsequently in the rat (Suzuki and Amaral, 1994; Burwell et al., 1995). 
The possibility of analyzing the function of specific connections within the medial temporal lobe has been improved by the use of new genetic and physiological techniques, as well as neuroimaging techniques, which take advantage of the detailed neuroanatomical information now available about the connectivity of these regions. For example, studies have begun to assess the separate contributions of the direct (temporoammonic) pathway from entorhinal cortex to the CA1 subfield and the indirect (trisynaptic) pathway from the entorhinal cortex to the CA1 via dentate gyrus and CA3 (Bakker et al., 2008; Moser et al., 2008; Nakashiba et al., 2008).

The hippocampus and related structures are essential for the formation of memory and its reorganization and consolidation during a lengthy period after learning. Alternative formulations, which emphasize the role of these structures in memory retrieval, have been considered over the years but have been largely abandoned (Squire, 2006). Two lines of work underlie the idea that medial temporal lobe structures have a temporary role in memory storage. First, damage to these structures typically spares remote memory and impairs more recent memory in a temporally graded manner (Squire and Bayley, 2007). Thus, in experimental animals, damage limited to the hippocampus, entorhinal cortex, or fornix typically impairs memory for material learned up to $30 \mathrm{~d}$ before the damage is introduced. In humans, damage limited to the hippocampus impairs memory for material learned up to a few years before the damage occurred. Discussion continues about the possible special status of spatial memory and autobiographical memory (Moscovitch et al., 2006), though in each of these cases the temporally graded pattern has been described previously (Squire and Bayley, 2007).

The second line of work involves studies that track neural activity or structural changes in medial temporal lobe structures after learning. For example, expression patterns of activityrelated genes such as c-Fos describe gradually decreasing activity in the hippocampus after learning (e.g., context fear conditioning) and parallel increases in activity in a number of cortical regions (Frankland and Bontempi, 2005). These findings and others (Restivo et al., 2009) document the increasing importance of distributed cortical regions for the representation and expression of memory as time passes after learning. Similar results have been obtained in neuroimaging studies, for example, when volunteers attempt to recall news events that occurred 1 to 30 years earlier (Smith and Squire, 2009). The idea is that gradual changes in neocortex establish stable long-term memory by increasing the connectivity among distributed cortical regions. As these changes occur, the role of the hippocampus (which initially works together with neocortex to support long-term memory storage) gradually declines.

Direct evidence for gradual, spontaneous changes in neocortex across a period of 6 weeks after training has been provided in the case of trace eyeblink conditioning in rats (TakeharaNishiuchi and McNaughton, 2008). Subsequent to initial acquisition, neural activity selective to the acquired association increased in medial prefrontal cortex, even in the absence of continued training. The peak increase in activity was observed at a time after learning when medial prefrontal cortex had become necessary for memory retrieval. The formation and maintenance of hippocampusdependent, long-term visual memory in the inferotemporal cortex of monkey can also be studied in single-cell recordings (Miyashita and Hayashi, 2000). Successful retrieval from memory (at least in the case of recently acquired information) occurs when brain activity comes to resemble (reinstate) the brain state that was present during original learning, and cortical association areas as well as hippocampus and entorhinal cortex participate in this process (Polyn et al., 2005; Gelbard-Sagiv et al., 2008).

A long-standing idea, which has received increased attention in recent years, is that retrieval of a memory provides an opportunity for updating or modulating what was originally learned (Monfils et al., 2009) and even the possibility of disrupting it (Nader et al., 2000). The process by which a long-term memory transiently returns to a labile state (and then gradually stabilizes) has been termed reconsolidation. Although it is clear that memory can be modified as the result of a retrieval event (Monfils et al., 2009), it is too simple to suppose that an established memory can be permanently abolished after retrieving it (e.g., by administering an inhibitor of protein synthesis), and the facts are still being developed. For example, some studies report that a reactivated memory can be disrupted but that the disruption is transient and fully reversible (Lattal and Abel, 2004; Power et al., 2006). It has also been found that only a memory formed relatively recently (e.g., 1 or $7 \mathrm{~d}$ ago, but not 14 or $28 \mathrm{~d}$ ago) can be disrupted after reactivating it (Milekic and Alberini, 2002). Other factors, such as the strength of the memory and the strength of the reactivation, also appear to be important. Learning is thought to initiate a consolidation process that eventually stabilizes the resulting memory. One possibility is that, early in this process, memory can be disrupted by various treatments such as inhibition of protein synthesis. Later in the process, these treatments are effective only if they are given after reactivation of memory. Still later, memory is stabilized, or consolidated, and cannot be disrupted (Alberini, 2005).

Ever since the discovery of place cells in rat hippocampus, the hippocampus has been a focus for studying how spatial information is represented in the nervous system and how spatial knowledge is used for navigation (O'Keefe and Nadel, 1978; Moser et al., 2008). The question of how ideas about spatial cognition relate to the traditional view that the hippocampus supports memory is an active topic of discussion. A central issue is whether to emphasize that place cells [and recently discovered grid cells (Fyhn et al., 2004)] provide computational equipment to support navigation, independently of memory, or to emphasize that activity in these cells serves to represent the significant features of a task or event, including spatial features, as an early step in establishing a memory. Relevant findings supporting the second view are (1) intact path integration in memory-impaired patients with large medial temporal lobe lesions, so long as the task can be managed within short-term (working) memory (Shrager et al., 2008); (2) evidence that, when a task is introduced, hippocampal "place cells" come to be activated in relation to all significant task features (e.g., odor, space, reward) (Eichenbaum et al., 1999); and (3) findings that hippocampal place cells can signal future choice, past events, and motivational state, not just the current spatial position of the animal (Pastalkova et al., 2008; Kennedy and Shapiro, 2009).

For decades, the idea has been discussed that sleep might provide off-line periods favorable to memory consolidation, and experimental study of this idea has accelerated in recent years. Recordings of neural activity in rodents showed that firing sequences recorded in assemblies of hippocampal place cells during waking behavior are replayed during slow-wave sleep (SWS). The finding of similar, coordinated activity in neocortex suggests that a dialogue occurs between hippocampus and neocortex (Ji and Wilson, 2007). This coordination could be part of the process by which recent memories become consolidated remote memories. To date, the replay phenomenon has been observed mainly in well trained animals running repeated paths along fixed tracks. 
The challenge remains to establish a clear link between these observations and memory consolidation and to determine how the replay that occurs during sleep relates to the replay that can occur during wakefulness (Karlsson and Frank, 2009).

In humans, SWS can modulate declarative memory. For example, the forgetting of declarative memory (in this case, wordpair memory) was attenuated by a night of sleep and attenuated further when the duration of SWS was increased by transcranial application of slow oscillations early in the night (at $0.75 \mathrm{~Hz}$ but not at $5 \mathrm{~Hz}$ ) (Marshall et al., 2006). Questions remain whether such effects are related specifically to memory consolidation or to the nonspecific benefits of reduced interference during an early time after learning when memory is vulnerable (Wixted, 2004).

Performance on tasks of nondeclarative memory can also be improved by sleep. In early studies, overnight improvement in texture discrimination was linked to rapid eye movement (REM) sleep (Karni et al., 1994), but subsequently, performance on this task was linked to the combination of SWS and REM sleep (Stickgold, 2005). Performance on other nondeclarative tasks (e.g., mirror tracing, motor sequence learning, and the serial reaction-time task) can also be improved more by sleep than by an equivalent period of wakefulness. Some studies have linked nondeclarative memory to REM sleep, but the findings are variable and may be task-dependent (Stickgold, 2005; Marshall and Born, 2007). Further study, both in animals and humans, can be expected to illuminate how sleep influences the retention of memory.

Soon after a brain-based distinction between declarative and procedural (or nondeclarative) memory was introduced (Cohen and Squire, 1980), the brain systems that support various kinds of nondeclarative memory came under study. Nondeclarative memory refers to a heterogeneous collection of skills, habits, and dispositions that are inaccessible to conscious recollection, yet are shaped by experience, influence our behavior and mental life, and are a fundamental part of who we are. The best-understood example of nondeclarative memory in vertebrates is classical conditioning of the eyeblink response, specifically delay eyeblink conditioning. In delay conditioning, the conditioned stimulus (CS) precedes the unconditioned stimulus (US), and the two stimuli then overlap and coterminate. The essential memory trace for the conditioned eyeblink response (and other discrete conditioned motor responses) is formed and stored in the cerebellar interpositus nucleus. The overlying cerebellar cortex is also important (especially lobule HVI and the anterior lobe), but the specific contribution of the cortex is not yet clear. The importance of the cerebellum for classical conditioning was discovered in 1981 (McCormick et al., 1981), and eyeblink conditioning then became the basis for an extensive program of cumulative study that identified the CS and US pathways, their points of convergence in the cerebellum, and the pathway for the conditioned motor response (Thompson and Steinmetz, 2009). This work remains the most successful example of localizing a memory trace within the vertebrate brain.

Shortly after the cerebellum was linked to conditioning, the striatum was proposed to be important for the sort of gradual, feedback-guided learning that results in habit learning (Mishkin et al., 1984). Subsequently, an elegant double dissociation was demonstrated in rats with fornix or caudate lesions who were given two tasks that appeared to assess declarative memory and habit memory, respectively (Packard et al., 1989). Only rats with fornix lesions were impaired in the first task, and only rats with caudate lesions were impaired in the second task. A similar contrast between declarative memory and habit memory was de- scribed for memory-impaired patients with hippocampal lesions and patients with nigrostriatal damage caused by Parkinson's disease (Knowlton et al., 1996). In addition, neuroimaging data showed that the caudate nucleus was active when volunteers acquired a putative habit task that could only be learned gradually by trial and error because of its probabilistic structure (Poldrack et al., 2001). When the task was modified so that a conscious strategy of memorization could be successful, the medial temporal lobe was active instead. Given enough time, severely amnesic patients were also able to learn gradually by trial and error, but they learned without awareness and at the beginning of each test session could not describe the task or the instructions (Bayley et al., 2005). Unlike declarative memory which is flexible and can guide behavior in multiple contexts, the acquired knowledge in this case was rigidly organized, and performance collapsed when the task format was altered.

Reward-based learning of this kind depends on dopamine neurons in the midbrain (substantia nigra and ventral tegmental area), which project to the striatum and signal the information value of a reward (Schultz, 2007). The neuronal response to the reward is strong when the reward is most unexpected (and therefore most instructive) and absent when it is fully predicted. The striatum receives both sensory and motor input from neocortex, as well as reward signals, and these inputs may allow stimuli and responses to become associated and to guide behavior. The operation of striatum-based neural circuits has broad relevance, not only for ordinary habit learning, but also for species-specific behaviors such as birdsong learning, as well as for more extreme forms of acquired repetitive behaviors, including addictive behaviors and neuropsychiatric conditions like Tourette's syndrome and obsessive-compulsive disorder (Graybiel, 2008).

Evaluative information, such as whether a stimulus or an event has positive or negative valence, is acquired largely as nondeclarative memory. Biological study of this kind of memory has made effective use of two important paradigms for the rat: fear conditioning and fear-potentiated startle (Fanselow, 1994; LeDoux, 2000; Davis, 2006). In fear conditioning, an initially neutral stimulus (the CS) is paired with a biologically significant event such as a footshock (the US). Subsequently, the animal exhibits defensive responses (a "fear" state) when the tone is presented alone. In fear-potentiated startle, the amplitude of the startle reflex is increased by presenting the startle stimulus (e.g., a loud sound) in the presence of a cue (e.g., a light) that has previously been paired with footshock.

Both of these phenomena depend critically on the amygdala. In the case of fear conditioning, information about the CS is transmitted to the lateral nucleus of the amygdala via a direct pathway through the thalamus as well as by an indirect pathway through auditory cortex. Information about the CS and US is thought to converge in the amygdala, and fear reactions are controlled by projections from the central nucleus of the amygdala to numerous target areas responsible for expressing the various symptoms of fear. It is generally thought that essential plasticity supporting the fear response develops directly in the amygdala, but this point has been difficult to establish with certainty.

The study of fear-potentiated startle began with identification of the neural pathway for the startle reflex. The reflex has a short (8 ms) latency and appears to involve just three synapses: (1) cochlear root neurons that are accessed by the auditory nerve; (2) axons of cochlear root neurons to the nucleus reticularis pontis caudalis; and (3) axons from the pons to motor neurons in the spinal cord. The fear state that potentiates this reflex is subserved by the amygdala, and the potentiation itself depends on direct 
and indirect projections from the central nucleus and medial nucleus of the amygdala to the startle circuit at the level of the pons (Davis, 2006).

The biological study of fear learning and its reversal [i.e., extinction (Quirk and Mueller, 2008)] has considerable relevance for clinical disorders such as phobias, post-traumatic stress disorder, and other anxiety disorders. Promising new developments include the novel scheduling of extinction trials, which can dramatically improve the outcome of extinction training (Monfils et al., 2009) and the possibility of using pharmacological treatment as an adjunct to standard psychotherapeutic approaches that involve extinction training (also termed desensitization) (Ressler et al., 2004).

In addition to its importance for emotional learning, the amygdala also exerts an important modulatory influence on both declarative and nondeclarative memory (McGaugh and Roozendaal, 2009). Thus, activity in the amygdala, and the effect of this activity on other structures, is responsible for the fact that emotionally arousing events are typically remembered better than emotionally neutral events. This phenomenon has been studied in detail and depends on the release of stress hormones (including epinephrine) from the adrenal gland, which then influence the forebrain via the vagus nerve and the nucleus of the solitary tract. Ultimately, the effect is mediated by $\beta$-adrenergic receptors in the basolateral nucleus of the amygdala. The importance of the amygdala for modulating memory has also been demonstrated with neuroimaging. Volunteers rated the arousing effects of either neutral scenes or emotionally distressing scenes and then took a memory test for the scenes 2 weeks later (Cahill et al., 2004). Increased activity in the amygdala at the time of learning was associated with higher arousal ratings for the scenes and improved accuracy on the later memory test. Interestingly, this effect occurred in the left amygdala for women and in the right amygdala for men.

The study of another form of nondeclarative memory began with the discovery that memory-impaired patients could perform normally on specially constructed tests that used word stems as cues (e.g., MOT, DIS) to recover recently presented words (e.g., MOTEL, DISCUSS). Critically, performance was normal only with specific instructions: use each cue to form the first word that comes to mind. With conventional memory instructions (use each cue to help in remembering a recently presented word), healthy subjects outperformed the patients (Graf et al., 1984). This instance of intact performance by memoryimpaired patients is now known as priming. Priming refers to an improvement in the ability to identify or process a stimulus as the result of a recent encounter with the same or a related stimulus (Tulving and Schacter, 1990). For example, volunteers can name common objects $\sim 100 \mathrm{~ms}$ faster if the objects have been presented previously. In addition, when asked to free associate to a word (e.g., canvas), volunteers will produce an associated word (e.g., tent) more often if that word was presented recently. For many years, it was supposed that these effects were related to ordinary (declarative) memory because it seemed reasonable that the presentation of an item should create a persisting sense of familiarity for that item (Jacoby, 1983). However, direct measurements subsequently showed that priming (e.g., increasing the speed by which an item is processed) provides only a weak and unreliable cue for familiarity (Conroy et al., 2005). Furthermore, severely amnesic patients exhibited fully intact word priming, even while performing at chance levels on parallel memory tests for the same words (Hamann and Squire, 1997; Levy et al., 2004). That is, priming occurred but it did not benefit conscious mem- ory decisions. Thus, it eventually became evident that priming is an unconscious memory phenomenon and is entirely independent of the medial temporal lobe.

Priming is presumably advantageous because animals evolved in a world where stimuli that are encountered once are likely to be encountered again. Priming improves the speed and efficiency with which organisms interact with a familiar environment. Neuroimaging studies indicate that priming is typically associated with reduced activity in those regions of neocortex that are engaged by the task (Wiggs and Martin, 1998; Schacter et al., 2007). Thus, perceptual priming in the visual modality is associated with reduced activity in early visual areas. Inferior frontal cortex exhibits reduced activity when the task requires not just perception but also access to the meaning of an item. Testable models have been developed to suggest how a net reduction in cortical activity can lead to more efficient, faster processing (i.e., priming), for example, if fewer neurons respond to the second presentation of a stimulus than to the first presentation, and the responsive neurons become more sharply tuned to the stimulus (Grill-Spector et al., 2006). Evoked potential studies suggest that the electrophysiological signature of priming occurs early and well before the activity that signals conscious memory (Paller et al., 2003).

In the late 1960s, methods were developed for studying visual perception and motor responses with single-cell recordings from awake, behaving monkeys. Soon after, the first unit recordings were obtained in monkeys performing the classic delayed response task, which requires holding information in memory for a brief period. This work identified cells in prefrontal cortex that were maximally active during the delay portion of the task (15 to $60 \mathrm{~s}$ ) (Fuster and Alexander, 1971). This finding, and much subsequent work, linked prefrontal cortex to what was initially termed short-term memory and, in later elaborations, working memory (Goldman-Rakic, 1995; Fuster, 2008).

Working memory refers to the capacity to maintain temporarily a limited amount of information in mind, which can then be used to support various abilities, including learning, reasoning, and preparation for action (Baddeley and Hitch, 1974). Working memory is therefore central to the ability to select and implement goal-directed behavior, to exercise what are termed executive functions. Indeed, recent discussions emphasize a broad role of prefrontal cortex in cognitive control, an idea that implies "top-down" influences from prefrontal cortex that direct attention and organize action (Miller, 2000; Fuster, 2001; Rich and Shapiro, 2009). The prefrontal cortex permits memory to be accessed strategically, and it orchestrates the use of learned rules so that knowledge relevant to current goals can be brought to mind and put to flexible use.

Patients with frontal lobe damage are not amnesic, but they have a number of deficiencies in how they use memory. They do poorly on tests of free (unaided) recall where healthy individuals can use strategic search, they have difficulty remembering the temporal order of events, and they make source memory errors (i.e., they may remember a recently learned fact but forget the source of the information such as when and where they learned it) (Shimamura et al., 1991). They also do poorly at tests of prospective memory, which refers to remembering to perform a future action. Thus, the prefrontal cortex is broadly important for processes and strategies involved in monitoring, organizing, and using memory.

This brief overview has been necessarily selective, and a number of interesting and promising directions for the study of memory have been passed over. There has been no mention of perceptual learning (Gilbert et al., 2009), or plasticity in the vestibulo-ocular 
reflex (Raymond and Lisberger, 1998), or the possible significance of neurogenesis for memory (Leuner et al., 2006; Clelland et al., 2009), or efforts to identify distinct functions of structures within the medial temporal lobe (Squire et al., 2007).

Science progresses in step with the development of new tools and paradigms that make it possible to ask new questions. This dynamic is readily apparent when one reflects on progress in the neuroscience of memory. In 1969, when the Society for Neuroscience was founded, hope for simplification and for a reductionistic approach to the study of memory focused on two species: Aplysia californica and Drosophila melanogaster. Yet there was considerable skepticism, because it was not known whether these animals could exhibit anything resembling a long-term memory. The breakthroughs came quickly. Long-term habituation lasting at least 3 weeks was described for Aplysia (Carew et al., 1972), and associative learning (odor-shock) in Drosophila was shown to persist for $24 \mathrm{~h}$ (Quinn et al., 1974). This work set the stage for decades of productive investigation of the anatomy, physiology, and genetics of memory. Similar examples are easy to identify. In the 1990s, techniques for creating knock-out and transgenic mice paved the way for the development of a still-expanding arsenal of molecular tools that promise to make tractable the analysis of neural circuits and networks that guide behavior (Luo et al., 2008). Also in the 1990s, newly developed neuroimaging techniques made it possible to record brain activity while individuals engage in learning and remembering (Posner and Raichle, 1994; Ungerleider, 1995). One can expect the next 40 years of the Society for Neuroscience to witness developments no less extraordinary.

\section{References}

Alberini CM (2005) Mechanisms of memory stabilization: are consolidation and reconsolidation similar or distinct processes? Trends Neurosci 28:51-56.

Baddeley AP, Hitch GJ (1974) Working memory. In: Recent advances in learning and motivation (Bower GA, ed), pp 47-90. New York: Academic.

Bakker A, Kirwan CB, Miller M, Stark CE (2008) Pattern separation in the human hippocampal CA3 and dentate gyrus. Science 319:1640-1642.

Bayley PJ, Frascino JC, Squire LR (2005) Robust habit learning in the absence of awareness and independent of the medial temporal lobe. Nature 436:550-553.

Burwell RD, Witter MP, Amaral DG (1995) Perirhinal and postrhinal cortices of the rat: a review of the neuroanatomical literature and comparison with findings from the monkey brain. Hippocampus 5:390-408.

Cahill L, Uncapher M, Kilpatrick L, Alkire MT, Turner J (2004) Sex-related hemispheric lateralization of amygdala function in emotionally influenced memory: an FMRI investigation. Learn Mem 11:261-266.

Carew TJ, Pinsker HM, Kandel ER (1972) Long-term habituation of a defensive withdrawal reflex in aplysia. Science 175:451-454.

Clelland CD, Choi M, Romberg C, Clemenson GD Jr, Fragniere A, Tyers P, Jessberger S, Saksida LM, Barker RA, Gage FH, Bussey TJ (2009) A functional role for adult hippocampal neurogenesis in spatial pattern separation. Science 325:210-213.

Cohen NJ, Squire LR (1980) Preserved learning and retention of pattern analyzing skill in amnesia: dissociation of knowing how and knowing that. Science 210:207-210.

Conroy MA, Hopkins RO, Squire LR (2005) On the contribution of perceptual fluency and priming to recognition memory. Cogn Affect Behav Neurosci 5:14-20.

Davis M (2006) Neural systems involved in fear and anxiety measured with fear-potentiated startle. Am Psychol 61:741-756.

Eichenbaum H, Dudchenko P, Wood E, Shapiro M, Tanila H (1999) The hippocampus, memory, and place cells: is it spatial memory or a memory space? Neuron 23:209-226

Fanselow MS (1994) Neural organization of the defensive behavior system responsible for fear. Psychon Bull Rev 1:429-438.

Frankland PW, Bontempi B (2005) The organization of recent and remote memories. Nat Rev Neurosci 6:119-130.
Fuster JM (2001) The prefrontal cortex-an update: time is of the essence. Neuron 30:319-333.

Fuster JM (2008) The prefrontal cortex, Ed 4. London: Academic.

Fuster JM, Alexander GE (1971) Neuron activity related to short-term memory. Science 173:652-654.

Fyhn M, Molden S, Witter MP, Moser EI, Moser MB (2004) Spatial representation in the entorhinal cortex. Science 305:1258-1264.

Gelbard-Sagiv H, Mukamel R, Harel M, Malach R, Fried I (2008) Internally generated reactivation of single neurons in human hippocampus during free recall. Science 322:96-101.

Gilbert CD, Li W, Piech V (2009) Perceptual learning and adult cortical plasticity. J Physiol 587:2743-2751.

Goldman-Rakic PS (1995) Architecture of the prefrontal cortex and the central executive. Ann N Y Acad Sci 769:71-83.

Graf P, Squire LR, Mandler G (1984) The information that amnesic patients do not forget. J Exp Psychol Learn Mem Cogn 10:164-178.

Graybiel AM (2008) Habits, rituals, and the evaluative brain. Annu Rev Neurosci 31:359-387.

Grill-Spector K, Henson R, Martin A (2006) Repetition and the brain: neural models of stimulus-specific effects. Trends Cogn Sci 10:14-23.

Hamann SB, Squire LR (1997) Intact perceptual memory in the absence of conscious memory. Behav Neurosci 111:850-854.

Jacoby LL (1983) Perceptual enhancement: persistent effects of an experience. J Exp Psychol Learn Mem Cogn 9:21-38.

Ji D, Wilson MA (2007) Coordinated memory replay in the visual cortex and hippocampus during sleep. Nat Neurosci 10:100-107.

Karlsson MP, Frank LM (2009) Awake replay of remote experiences in the hippocampus. Nat Neurosci 12:913-918.

Karni A, Tanne D, Rubenstein BS, Askenasy JJ, Sagi D (1994) Dependence on REM sleep of overnight improvement of a perceptual skill. Science 265:679-682.

Kennedy PJ, Shapiro ML (2009) Motivational states activate distinct hippocampal representations to guide goal-directed behaviors. Proc Natl Acad Sci U S A 106:10805-10810.

Knowlton BJ, Mangels JA, Squire LR (1996) A neostriatal habit learning system in humans. Science 273:1399-1402.

Lattal KM, Abel T (2004) Behavioral impairments caused by injections of the protein synthesis inhibitor anisomycin after contextual retrieval reverse with time. Proc Natl Acad Sci U S A 101:4667-4672.

LeDoux JE (2000) Emotion circuits in the brain. Annu Rev Neurosci 23:155-184.

Leuner B, Gould E, Shors TJ (2006) Is there a link between adult neurogenesis and learning? Hippocampus 16:216-224.

Levy DA, Stark CE, Squire LR (2004) Intact conceptual priming in the absence of declarative memory. Psychol Sci 15:680-686.

Luo L, Callaway EM, Svoboda K (2008) Genetic dissection of neural circuits. Neuron 57:634-660.

Marshall L, Born J (2007) The contribution of sleep to hippocampusdependent memory consolidation. Trends Cogn Sci 11:442-450.

Marshall L, Helgadóttir H, Mölle M, Born J (2006) Boosting slow oscillations during sleep potentiates memory. Nature 444:610-613.

McCormick DA, Lavond DG, Clark GA, Kettner RR, Rising CE, Thompson RF (1981) The engram found? Role of the cerebellum in classical conditioning of nicitating membrane and eyelid responses. Bull Psychonomic Soc 18:103-105.

McGaugh JL, Roozendaal B (2009) Drug enhancement of memory consolidation: historical perspective and neurobiological implications. Psychopharmacology 202:3-14.

Milekic MH, Alberini CM (2002) Temporally graded requirement for protein synthesis following memory reactivation. Neuron 36:521-525.

Miller EK (2000) The prefrontal cortex and cognitive control. Nat Rev Neurosci 1:59-65.

Mishkin M (1978) Memory in monkeys severely impaired by combined but not by separate removal of amygdala and hippocampus. Nature 273:297-298.

Mishkin M, Malamut B, Bachevalier J (1984) Memories and habits: two neural systems. In: Neurobiology of learning and memory (Lynch G, McGaugh JL, Weinberger NM, eds), pp 65-77. New York: Guilford.

Miyashita Y, Hayashi T (2000) Neural representation of visual objects: encoding and top-down activation. Curr Opin Neurobiol 10:187-194.

Monfils MH, Cowansage KK, Klann E, LeDoux JE (2009) Extinction- 
reconsolidation boundaries: key to persistent attenuation of fear memories. Science 324:951-955.

Moscovitch M, Nadel L, Winocur G, Gilboa A, Rosenbaum RS (2006) The cognitive neuroscience of remote episodic, semantic and spatial memory. Curr Opin Neurobiol 16:179-190.

Moser EI, Kropff E, Moser MB (2008) Place cells, grid cells, and the brain's spatial representation system. Annu Rev Neurosci 31:69-89.

Nader K, Schafe GE, Le Doux JE (2000) Fear memories require protein synthesis in the amygdala for reconsolidation after retrieval. Nature 406:722-726.

Nakashiba T, Young JZ, McHugh TJ, Buhl DL, Tonegawa S (2008) Transgenic inhibition of synaptic transmission reveals role of CA3 output in hippocampal learning. Science 319:1260-1264.

O'Keefe J, Nadel L (1978) The hippocampus as a cognitive map. London: Oxford UP.

Packard MG, Hirsh R, White NM (1989) Differential effects of fornix and caudate nucleus lesions on two radial maze tasks: evidence for multiple memory systems. J Neurosci 9:1465-1472.

Paller KA, Hutson CA, Miller BB, Boehm SG (2003) Neural manifestations of memory with and without awareness. Neuron 38:507-516.

Pastalkova E, Itskov V, Amarasingham A, Buzsáki G (2008) Internally generated cell assembly sequences in the rat hippocampus. Science 321:1322-1327.

Poldrack RA, Clark J, Paré-Blagoev EJ, Shohamy D, Creso Moyano J, Myers C, Gluck MA (2001) Interactive memory systems in the brain. Nature 414:546-550.

Polyn SM, Natu VS, Cohen JD, Norman KA (2005) Category-specific cortical activity precedes retrieval during memory search. Science 310:19631966.

Posner MI, Raichle ME (1994) Images of mind. New York: Scientific American Library.

Power AE, Berlau DJ, McGaugh JL, Steward O (2006) Anisomycin infused into the hippocampus fails to block "reconsolidation" but impairs extinction: the role of re-exposure duration. Learn Mem 13:27-34.

Quinn WG, Harris WA, Benzer S (1974) Conditioned behavior in Drosophila melanogaster. Proc Natl Acad Sci U S A 71:708-712.

Quirk GJ, Mueller D (2008) Neural mechanisms of extinction learning and retrieval. Neuropsychopharmacology 33:56-72.

Raymond JL, Lisberger SG (1998) Neural learning rules for the vestibuloocular reflex. J Neurosci 18:9112-9129.

Ressler KJ, Rothbaum BO, Tannenbaum L, Anderson P, Graap K, Zimand E, Hodges L, Davis M (2004) Cognitive enhancers as adjuncts to psychotherapy: use of $\mathrm{D}$-cycloserine in phobic individuals to facilitate extinction of fear. Arch Gen Psychiatry 61:1136-1144.

Restivo L, Vetere G, Bontempi B, Ammassari-Teule M (2009) The formation of recent and remote memory is associated with time-dependent formation of dendritic spines in the hippocampus and anterior cingulate cortex. J Neurosci 29:8206-8214.
Rich EL, Shapiro M (2009) Rat prefrontal cortical neurons selectively code strategy switches. J Neurosci 29:7208-7219.

Schacter DL, Wig GS, Stevens WD (2007) Reductions in cortical activity during priming. Curr Opin Neurobiol 17:171-176.

Schultz W (2007) Multiple dopamine functions at different time courses. Annu Rev Neurosci 30:259-288.

Scoville WB, Milner B (1957) Loss of recent memory after bilateral hippocampal lesions. J Neurol Neurosurg Psychiatry 20:11-21.

Shimamura AP, Janowsky JS, Squire LR (1991) What is the role of frontal lobe damage in memory disorders? In: Frontal lobe functioning and dysfunction (Levin HD, Eisenberg HM, Benton AL, eds), pp 173-195. New York: Oxford UP.

Shrager Y, Kirwan CB, Squire LR (2008) Neural basis of the cognitive map: path integration does not require hippocampus or entorhinal cortex. Proc Natl Acad Sci U S A 105:12034-12038.

Smith CN, Squire LR (2009) Medial temporal lobe activity during retrieval of semantic memory is related to the age of the memory. J Neurosci 29:930-938.

Squire LR (2004) Memory systems of the brain: a brief history and current perspective. Neurobiol Learn Mem 82:171-177.

Squire LR (2006) Lost forever or temporarily misplaced? The long debate about the nature of memory impairment. Learn Mem 13:522-529.

Squire LR (2009) The legacy of patient H.M. for neuroscience. Neuron $61: 6-9$.

Squire LR, Bayley PJ (2007) The neuroscience of remote memory. Curr Opin Neurobiol 17:185-196.

Squire LR, Zola-Morgan S (1991) The medial temporal lobe memory system. Science 253:1380-1386.

Squire LR, Wixted JT, Clark RE (2007) Recognition memory and the medial temporal lobe: a new perspective. Nat Rev Neurosci 8:872-883.

Stickgold R (2005) Sleep-dependent memory consolidation. Nature 437:12721278 .

Suzuki WA, Amaral DG (1994) Perirhinal and parahippocampal cortices of the macaque monkey: cortical afferents. J Comp Neurol 350:497-533.

Takehara-Nishiuchi K, McNaughton BL (2008) Spontaneous changes of neocortical code for associative memory during consolidation. Science 322:960-963.

Thompson RF, Steinmetz JE (2009) The role of the cerebellum in classical conditioning of discrete behavioral responses. Neuroscience 162:732755 .

Tulving E, Schacter DL (1990) Priming and human memory systems. Science 247:301-306.

Ungerleider LG (1995) Functional brain imaging studies of cortical mechanisms for memory. Science 270:769-775.

Wiggs CL, Martin A (1998) Properties and mechanisms of perceptual priming. Curr Opin Neurobiol 8:227-233.

Wixted JT (2004) The psychology and neuroscience of forgetting. Annu Rev Psychol 55:235-269. 